Rafael Ferreira-Garcia

Q https://orcid org/0000-0002-8186-0939

Antonio Egídio Nardi²

Ohttps://orid.org/0000-0002-2152-4669

Marleide da Mota Gomes

Ohttps://orid.org/0000-0001-8889-2573

\section{Ludwig van Beethoven: psychosocial determinants of mental health}

Ludwig van Beethoven: determinantes psicossociais da saúde mental

DOI: $10.1590 / 0047-2085000000321$

\section{DEAR EDITOR,}

Ludwig van Beethoven's (17 December 1770, Bonn, Kurköln - 26 March 1827, Vienna) biography has been the subject of intense study by medical historians, given his intriguing physical suffering that includes several symptoms and complaints that have been subject of intense debate'. The interaction between the physical ailments and Beethoven's career has also been the subject of study.

Mental health issues have also been hypothesized based on documented behavioral peculiarities and symptoms, corroborated by biographers and first-hand accounts of the composer's life. Severe bouts of depression alternating with periods of increased energy, racing thoughts, increased suspiciousness, irritability, and even violence favor a probable diagnosis of bipolar disorder'. Borderline personality disorder was also raised as a possible diagnosis. However, the absence of a chronic pattern of sensitivity to rejection and an overall high level of functioning between mood episodes make that possibility somewhat less likely². Although the presentation and the course of mental disorders can be substantially altered by accompanying psychosocial factors, few studies have examined those in light of a probable mood disorder. We raise attention to a few peculiar behavioral aspects and related risk factors with potential implications to Beethoven's mental health and career.

Problematic alcohol use is a frequent comorbidity in patients with mood disorders and can be severely detrimental to its course and outcome. Beethoven's drinking habits have long been hypothesized to be pathological, as evidenced by contemporary accounts of increased problematic drinking (some of his doctors and even friends strongly advised him to stop), and extensive signs of terminal cirrhosis in his autopsy'. Positive family history of alcohol dependence was also present in his father and paternal grandmother. On the other hand, we cannot exclude the possibility of increased alcohol use to have a role in Beethoven's music's creative process. Moderate alcoholic intoxication has been shown to increase creative problem-solving in male social drinkers ${ }^{3}$, reinforcing the broken Romantic genius's archetype.

Physical activity is regarded as a protective factor in mental disorders ${ }^{4}$. Swafford ${ }^{5}$ summarized Beethoven's walking habits: "Once or twice a day, in all weathers, he set off on a brisk walk around the city walls [...] Walking was as much a part of the process as the rest of it". Extended physical activity can be speculated as Beethoven's potential coping mechanism for both physical and mental illnesses, which was probably reflected in his creative productivity, as he observed to his nephew: "I spend all my mornings with the muses; -and they bless me also in my walks".

Little attention was given to the interaction between psychosocial determinants of mental health and their interaction with Beethoven's psychiatric symptoms and musical career. Beethoven's illness seems to be modified by unusual amounts of physical activity, potentially increasing dopamine-mediated satisfaction and counterbalancing a potentially problematic

Received in: 0ct/1/2020. Approved in: Dec/22/2020

1 Federal University of Rio de Janeiro, Institute of Psychiatry, Rio de Janeiro, RJ, Brazil.

2 Laboratory of History of Psychiatry, Neurology, and Mental Health, Institute of Psychiatry, and Institute of Neurology, Federal University of Rio de Janeiro

io de Janeiro, RJ, Brazil.

Address for correspondence: rafaelfg@ipub.ufrj.br 
alcohol use. These factors must have played a role in Beethoven's musical genius's flourishing and help illuminate the musician's biography, providing an interesting illustration for clinicians and researchers dealing with the complex interaction between creative professions and mental health.

\section{CONFLICT OF INTERESTS}

The authors declare no conflict of interest.

\section{REFERENCES}

1. Hui AC, Wong SM. Deafness and liver disease in a 57-year-old man: a medical history of Beethoven. Hong Kong Med J. 2000;6(4):433-8.

2. Dehm P. Beethoven: The Man and the Madness Behind the Music. Soundings. 2008.

3. Jarosz AF, Colflesh GJH, Wiley J. Uncorking the muse: Alcohol intoxication facilitates creative problem-solving. Conscious Cogn. 2012;21(1):487-93.

4. Hearing CM, Chang WC, Szuhany KL, Deckersbach T, Nierenberg AA, Sylvia LG. Physical Exercise for Treatment of Mood Disorders: A Critical Review. Curr Behav Neurosci Rep. 2016;3(4):350-9.

5. Swafford J. Beethoven: Anguish and Triumph: a Biography [Internet]. Houghton Mifflin Harcourt; 2014. Available from: https://books.google.com.br/books? id=COQSBAAAQBAJ 